\title{
Effect of myoglobin, hemin, and ferric iron on quality of chicken breast meat
}

\author{
Muhan Zhang ${ }^{1}$, Weili Yan ${ }^{1}$, Daoying Wang ${ }^{1, *}$, and Weimin $\mathrm{Xu}^{1}$
}

* Corresponding Author: Daoying Wang Tel: +86-25-84390065, Fax: +86-25-84391677,

E-mail: daoyingwang@yahoo.com

1 Institute of Agricultural Products Processing, Jiangsu Academy of Agricultural Sciences,

Nanjing 210014, China

ORCID

Muhan Zhang

https://orcid.org/0000-0002-8762-2771

Weili Yan

https://orcid.org/0000-0001-6817-1234

Daoying Wang

https://orcid.org/0000-0003-1776-5854

Weimin Xu

https://orcid.org/0000-0003-3114-3162

Submitted Jul 27, 2020; Revised Sept 19, 2020; Accepted Nov 8, 2020
Objective: The objective was to evaluate the impact of different forms of iron including myoglobin, hemin, and ferric chloride on the quality of chicken breast meat.

Methods: Chicken breast muscles were subjected to $1,2,3 \mathrm{mg} / \mathrm{mL}$ of $\mathrm{FeCl}_{3}$, myoglobin and hemin treatment respectively, and the production of reactive oxygen species (ROS) and malondialdehyde, meat color, tenderness, water holding capacity and morphology of meat was evaluated.

Results: Hemin was found to produce more ROS and induce greater extent of lipid oxidation than myoglobin and ferric chloride. However, it showed that hemin could significantly increase the redness and decrease the lightness of the muscle. Hemin was also shown to be prominent in improving water holding capacity of meat, maintaining a relatively higher level of the immobilized water from low-field nuclear magnetic resonance measurements. Morphology observation by hematoxylin-eosin staining further confirmed the results that hemin preserved the integrity of the muscle.

Conclusion: The results indicated that hemin may have economic benefit for the industry based on its advantage in improving water holding capacity and quality of meat.

Keywords: Myoglobin; Hemin; Iron; Lipid Oxidation; Water Holding Capacity

\section{INTRODUCTION}

Myoglobin (Mb), an essential hemoprotein in skeletal muscle, has been widely characterized for its functional role in oxygen storage and cellular diffusion. It consists of a globin moiety plus a porphyrin heme, the latter containing an iron atom that can exist in a reduced (ferrous) or oxidized (ferric) form coordinated inside the heme ring [1]. In meat, $\mathrm{Mb}$ is extensively studied because it plays a crucial role in meat colouration as the principle heme protein in sarcoplasm and because of its interaction with nitric oxide to form typical pigment in cured meat [2,3].

Moreover, lipid oxidation is the major factor that determines the sensory, functional, and nutritional quality of meat products, and $\mathrm{Mb}$, released heme and iron has been recognized as major catalysts for lipid oxidation [4]. During post-mortem storage and processing of muscle, hemin (ferric heme) could dissociate from the globin, and heme oxygenase and reactive oxygen species (ROS) could cause heme destruction which subsequently releases iron from heme ring $[3,5]$. However, the relative contributions of different forms of iron, whether "free" or protein bound, heme or non-heme, in catalyzing lipid peroxidation in muscle-based foods have not been assigned. Min et al [6] reported that free ionic iron was more effective to promote lipid oxidation in raw and cooked chicken and beef meat. Whereas Grunwald and Richards [7] reported that released hemin is the primary promoter of lipid oxidation, and iron liberated from heme ring decreased the rate of lipid 
oxidation in washed fish muscle. The roles of myoglobin, hemin and free iron in lipid oxidation and their mechanisms is still not clear.

Despite their relevance to lipid oxidation, the contribution of these components to water holding capacity (WHC) and other meat quality traits is still an almost unexplored area. WHC is not only important for economic reasons as the industry loses money due to the weight loss of product and the inconsistency in the yield of the final product during storage or upon cooking, but also because of its role in the structure and sensory acceptability of meat. In this study, myoglobin, hemin and $\mathrm{FeCl}_{3}$, which represent protein-bound heme, free heme and free iron respectively were used to treat chicken breast muscle to investigate the efficiency of different iron forms in catalyzing lipid oxidation, and to assess their function in the color, tenderness and water retention of meat.

\section{MATERIALS AND METHODS}

\section{Materials}

Sixty-three white feather broiler chickens (fed for 40 days) were obtained from a commercial processing plant where they were slaughtered according to standard industry practices by hanging, electrical water bath stunning and bleeding from a unilateral neck cut severing the left carotid artery and jugular vein (Jiangsu Lihua Animal Husbandry Co., Ltd, Nanjing, China). Myoglobin (from equine skeletal muscle) and hemin were purchased from Sigma-Aldrich Corp. (St. Louis, MO, USA); All solvents and other reagents were analytical grade.

\section{Sample preparation}

Two skinless, de-boned breast fillets (Pectoralis major) were taken immediately from each carcass and placed into a plastic bag on ice. The muscles were divided into 21 groups ( $\mathrm{n}=$ 3 ), one of them was taken as fresh sample, two of them were immersed in phosphate buffered saline (PBS, $\mathrm{pH} 7.0$ ) for $2 \mathrm{~h}$ and $8 \mathrm{~h}$ respectively, and another 18 groups were subjected to $1,2,3 \mathrm{mg} / \mathrm{mL}$ of $\mathrm{FeCl}$, myoglobin or hemin in $\mathrm{PBS}$ ( $\mathrm{pH}$ 7.0) at $37^{\circ} \mathrm{C}$ in the dark for $2 \mathrm{~h}$ and $8 \mathrm{~h}$ respectively. The whole muscles were individually sealed in plastic bags, fully immersed in $\mathrm{FeCl} 3$, myoglobin, hemin or PBS solutions and were wiped with filter paper to remove excess liquid after the treatment. The measurements of meat quality were conducted immediately after the treatment, and the samples for other evaluation were frozen at $-20^{\circ} \mathrm{C}$.

\section{Reactive oxygen species detection}

2,7-Dichlorofluorescein diacetate (DCFH-DA) was utilized as a chemical probe for ROS measurement [8]. Approximately $2 \mathrm{~g}$ of frozen muscles from each sample were crushed and homogenized on ice in $20 \mathrm{~mL}$ of Tris- $\mathrm{HCl}$ buffer $(100$
$\mathrm{mM}$ Tris- $\mathrm{HCl}, \mathrm{pH}$ 8.0) and a protease inhibitors cocktail (Sigma-Aldrich Corp., USA) followed by centrifugation at $12,000 \mathrm{~g}$ for $10 \mathrm{~min}$ at $4^{\circ} \mathrm{C}$. DCFH-DA was mixed with muscle extract at the final concentration of $10 \mu \mathrm{M}$, and they were incubated at $37^{\circ} \mathrm{C}$ for $30 \mathrm{~min}$. The fluorescence intensity was measured at 485 and $525 \mathrm{~nm}$ as the respective excitation wavelength and emission wavelength on a Cytation5 microplate reader (Biotek Instruments Inc., Winooski, VT, USA).

\section{Determination of thiobarbituric acid reactive substances}

Lipid oxidation of all samples was measured by the 2-thiobarbituric (TBA) method according to Sorensen and Jorgensen [9]. Ten grams of sample was homogenized with $30 \mathrm{~mL}$ of a $7.5 \%$ trichloroacetic acid solution containing $0.1 \%$ propylgallate and $0.1 \%$ ethylenediaminetetraacetic acid disodium salt for $30 \mathrm{~s}$ in an Ultra Turrax blender $(9,500 \mathrm{rpm})$ and filtered through a Whatman filter No. 42 . Equal $5 \mathrm{~mL}$ volumes of filtrate and 0.02 M TBA solution were mixed with glass stopped tubes and incubated in a water bath at $100^{\circ} \mathrm{C}$ for $40 \mathrm{~min}$ before cooling to room temperature under running cold tap water. The absorbance was measured at $532 \mathrm{~nm}$ using a spectrophotometer. Thiobarbituric acid reactive substances was calculated from a standard curve of malondialdehyde (MDA), freshly prepared by acidification of 1,1,3,3-tetraethoxypropane in the range from $0.02 \mu \mathrm{g} / \mathrm{mL}$ to $0.3 \mu \mathrm{g} / \mathrm{mL}$ and expressed as mg of MDA per $\mathrm{kg}$ sample.

\section{Meat color}

The meat color $\left(\mathrm{L}^{*}, \mathrm{a}^{\star}, \mathrm{b}^{*}\right)$ was measured using a colorimeter (CR 400, Minolta, Tokyo, Japan). The colorimeter was calibrated using a standard white ceramic tile before measuring the samples.

\section{Cooking loss}

Each sample was weighed accurately prior to cooking. The sample in cooking bag was immersed in an $80^{\circ} \mathrm{C}$ water bath until reaching an internal endpoint of $75^{\circ} \mathrm{C}$. After cooking, the sample was cooled to the internal temperature of room temperature and wiped with blotting paper to remove excess water, followed by weighting immediately. Cooking loss was calculated as, Cooking loss $(\%)=([$ raw weight - cooked weight $] /$ raw weight $) \times 100$.

\section{Warner-Bratzler shear force}

After measuring of cooking loss, the same muscle was then used for the determination of shear force. Breast portions were cut into $1 \times 1 \mathrm{~cm}$, variable length strips parallel to the muscle fibers. Shear force was determined through the application of the Meullenet-Owens razor shear test [10], using a texture analyzer (TVT-300XP, TexVol Instruments, Viken, Sweden) equipped with a razor blade with a height of $24 \mathrm{~mm}$ 
and a width of $8.9 \mathrm{~mm}$. Muscle strips were cut across the fiber axis. The crosshead speed was set at $2 \mathrm{~mm} / \mathrm{s}$, and the test was triggered by a $10 \mathrm{~g}$ contact force. The shear was perpendicular to the axis of muscle fibers.

\section{Low-field nuclear magnetic resonance spin-spin} relaxation $\left(T_{2}\right)$ measurements

Nuclear magnetic resonance (NMR) relaxation measurements were performed on a Niumag Benchtop Pulsed NMR Analyzer PQ001 (Niumag Electric Corporation, Shanghai, China) operating at a resonance frequency for protons of 22.6 MHz according to Bertram et al [11] with modifications. Approximately $2 \mathrm{~g}$ sample was placed in a $15 \mathrm{~mm}$ glass tube and inserted in the NMR probe. Spin-spin relaxation time, $\mathrm{T}_{2}$, was measured using the Carr-Purcell-Meiboom-Gill sequence. The $T_{2}$ measurements were made with a $\tau$-value (time between $90^{\circ}$ and $180^{\circ}$ pulse) of $200 \mu$ s Data from 12,000 echoes were acquired as 32 scan repetitions. The repetition time between subsequent scans was $6.5 \mathrm{~s}$. Each measurement was performed in triplicate.

\section{Muscle specimen preparation and hematoxylin and eosin staining}

Muscle tissues were sliced into 1 to $4 \mathrm{~mm}$ sections behind the optic chiasma and were subsequently fixed in $4 \%$ paraformaldehyde at $4^{\circ} \mathrm{C}$ according to Lan et al [12] with modifications. The sections were then dehydrated in a dehydration box. Melted paraffin was poured into the embedding box, followed by the muscle sections. When the paraffin was completely hardened, the paraffin block was removed from the embedding box and stored at $4^{\circ} \mathrm{C}$. For slicing, the paraffin block was placed on a paraffin slicing machine and sectioned from the front to the back to make $4 \mu \mathrm{m}$ thick sections. The slices, which floated on the surface, were flattened, and lifted onto the slides. The sections were then placed in a $60^{\circ} \mathrm{C}$ incubator overnight.

The sections were baked at $65^{\circ} \mathrm{C}$ for $30 \mathrm{~min}$ and then dewaxed twice in dimethylbenzene for $20 \mathrm{~min}$ each time. The sections were exposed to a gradient ethanol dehydration, and then hematoxylin (Baso Inc., Zhuhai, China) staining was performed for $5 \mathrm{~min}$ after the sections were washed in distilled water. The sections were then washed, immersed in $1 \%$ hydrochloric acid-alcohol solution, washed in water, treated with $0.6 \%$ ammonium hydroxide, washed again, and then stained with eosin (Baso Inc., China) for 1 to 3 min. Following gradient ethanol dehydration, the sections were dehydrated and cleared in dimethylbenzene. Gradient ethanol dehydration was performed again, and the sections were mounted in neutral balsam. Subsequently, morphological of the tissues were observed under a light microscope and photographed using a Nikon Eclipse Ci microscopic imaging system.

\section{Statistical analysis}

All data were expressed as the mean \pm standard error. Statistical analysis of the differences between each group was

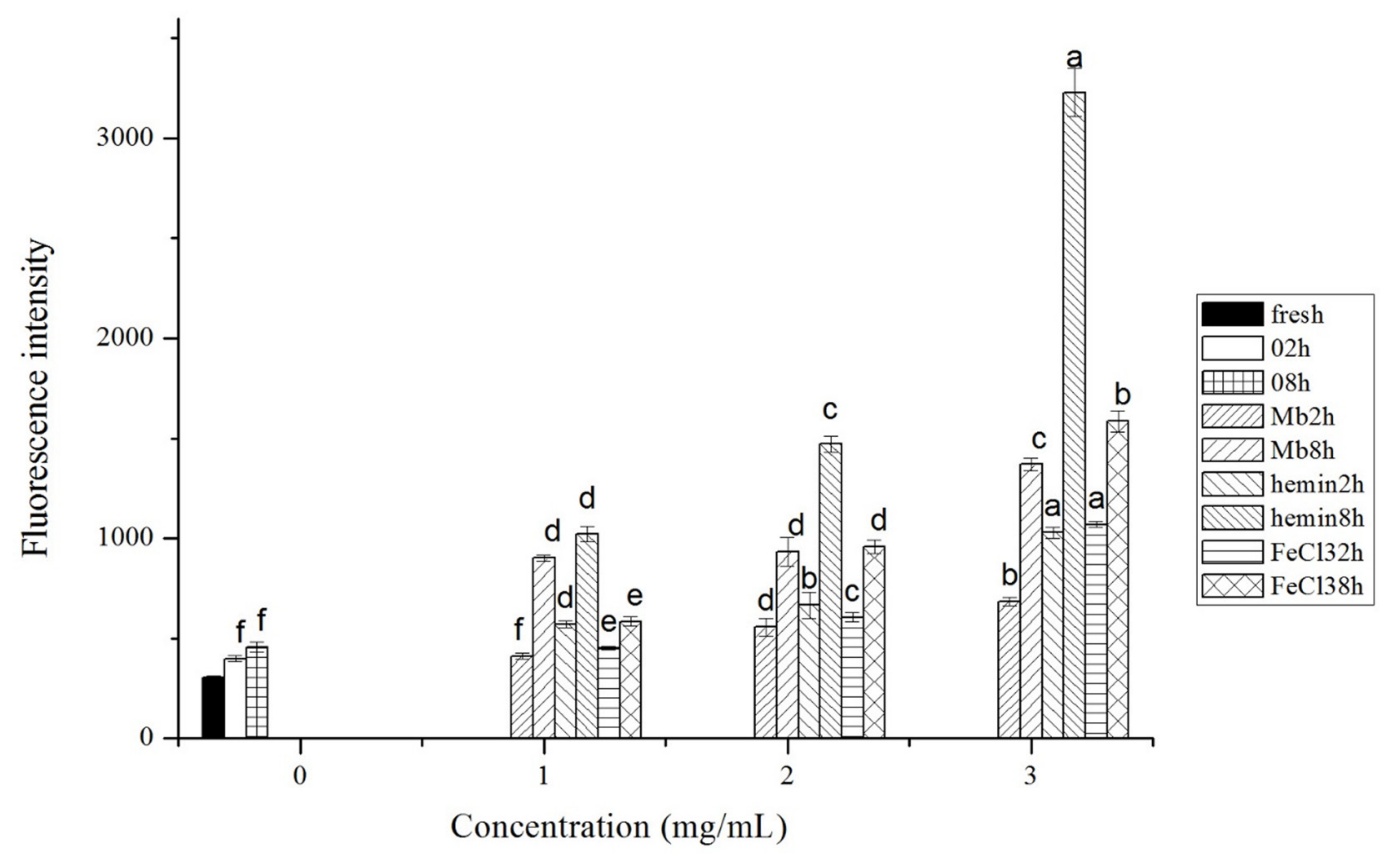

Figure 1. Reactive oxygen species (ROS) generation in fresh musles and muscles incubated with phosphate buffered saline (PBS) or different concentrations of myoglobin, hemin, and $\mathrm{FeCl}_{3}$ in $\mathrm{PBS}$ for $2 \mathrm{~h}$ or $8 \mathrm{~h}$ of incubation time, respectively. Results are expressed as mean \pm standard error.

${ }^{a-f}$ For each incubation time, values not bearing common superscripts differ significantly $(p<0.05)$. 
evaluated at each time point by one-way analysis of variance using the SPSS 18.0 and values of $\mathrm{p}<0.05$ was considered as statistically significant.

\section{RESULTS AND DISCUSSION}

Reactive oxygen species production and lipid oxidation The generation of ROS was examined via the DCFH-DA probe, which can be oxidized by ROS to form the fluorescent compound 2,7-dichlorofluorescein (DCF). As shown in Figure 1, the generation of ROS in chicken muscle increased with the concentration of $\mathrm{Mb}$, hemin and $\mathrm{FeCl}_{3}$ and the incubation time. At the treatment time of $2 \mathrm{~h}$, the level of ROS increased in $3 \mathrm{mg} / \mathrm{mL}$ hemin and $\mathrm{FeCl}_{3}$ treated muscle compared to that of $\mathrm{Mb}$. While at $8 \mathrm{~h}$, the level of ROS in hemin group exceeded the other two groups $(\mathrm{p}<0.05)$, and was in the order of hemin $>\mathrm{FeCl}_{3}>\mathrm{Mb}$. ROS such as hydroxyl radical (.OH), superoxide anion $\left(\mathrm{O}_{2}^{-}\right)$, and hydrogen peroxide $\left(\mathrm{H}_{2} \mathrm{O}_{2}\right)$ are highly reactive to initiate lipid peroxidation, protein fragmentation and DNA damage. The ferric ions are involved in the generation of hydroxyl and peroxide radicals in the presence of hydrogen peroxide known as Fenton reaction, or as catalysts in the Haber-Weiss reaction between $\mathrm{H}_{2} \mathrm{O}_{2}$ and superoxide to generate hydroxyl radicals [13]. He$\mathrm{min}$ can react with lipid hydroperoxides to form a wide array of lipophilic free radicals such as alkoxyl and peroxyl radicals $[4,7]$. During the autoxidation of $\mathrm{Mb}$, superoxide anion $\left(\mathrm{O}_{2}^{-}\right)$ could be produced, and $\mathrm{Mb}$ has been shown to form the fer- ryl protein cation radical and transfer radicals to a wide range of target proteins [7,14]. Efforts have been made to determine the contributions of the different forms of iron to lipid oxidation in meat. The effects of heme pigments and nonheme iron on lipid oxidation in beef, pork and chicken were compared, and heme pigment concentration was found to be more important than non-heme iron in predicting lipid oxidation in meat [15]. The catalytic activity and the generation of radicals by metmyoglobin (metMb) and hemin have been studied experimentally and through computer simulation, and it showed that the activity of hemin exceeded that of the metMb at the physiological $\mathrm{pH}$ of 7.4, thus, the catalysis of lipid peroxidation by metMb is caused by the destruction of heme-protein adduct [16].

The production of MDA in chicken muscles showed that hemin could more effectively stimulate lipid oxidation than $\mathrm{Mb}$ and $\mathrm{FeCl} 3$ at each concentration and incubation time (Figure 2). The production of MDA was significantly higher in $3 \mathrm{mg} / \mathrm{mL} \mathrm{Mb}$ incubated muscles than the same concentration of $\mathrm{FeCl}_{3}$ at $2 \mathrm{~h}$ and $8 \mathrm{~h}(\mathrm{p}<0.05)$, but there was no significant difference between $\mathrm{Mb}$ and $\mathrm{FeCl}_{3}$ treated muscles at the concentration of $1 \mathrm{mg} / \mathrm{mL}$ and $2 \mathrm{mg} / \mathrm{mL}$ ( $p>0.05)$. The results coincided with the ROS measurements, indicating the formation of ROS is responsible for lipid oxidation in meat. The results could also be attributed to their different mechanisms in the reaction with lipids. Hemin is hydrophobic which enables its interaction with lipids, while $\mathrm{Mb}$ is hydrophilic and the interaction between $\mathrm{Mb}$ and lipids depends

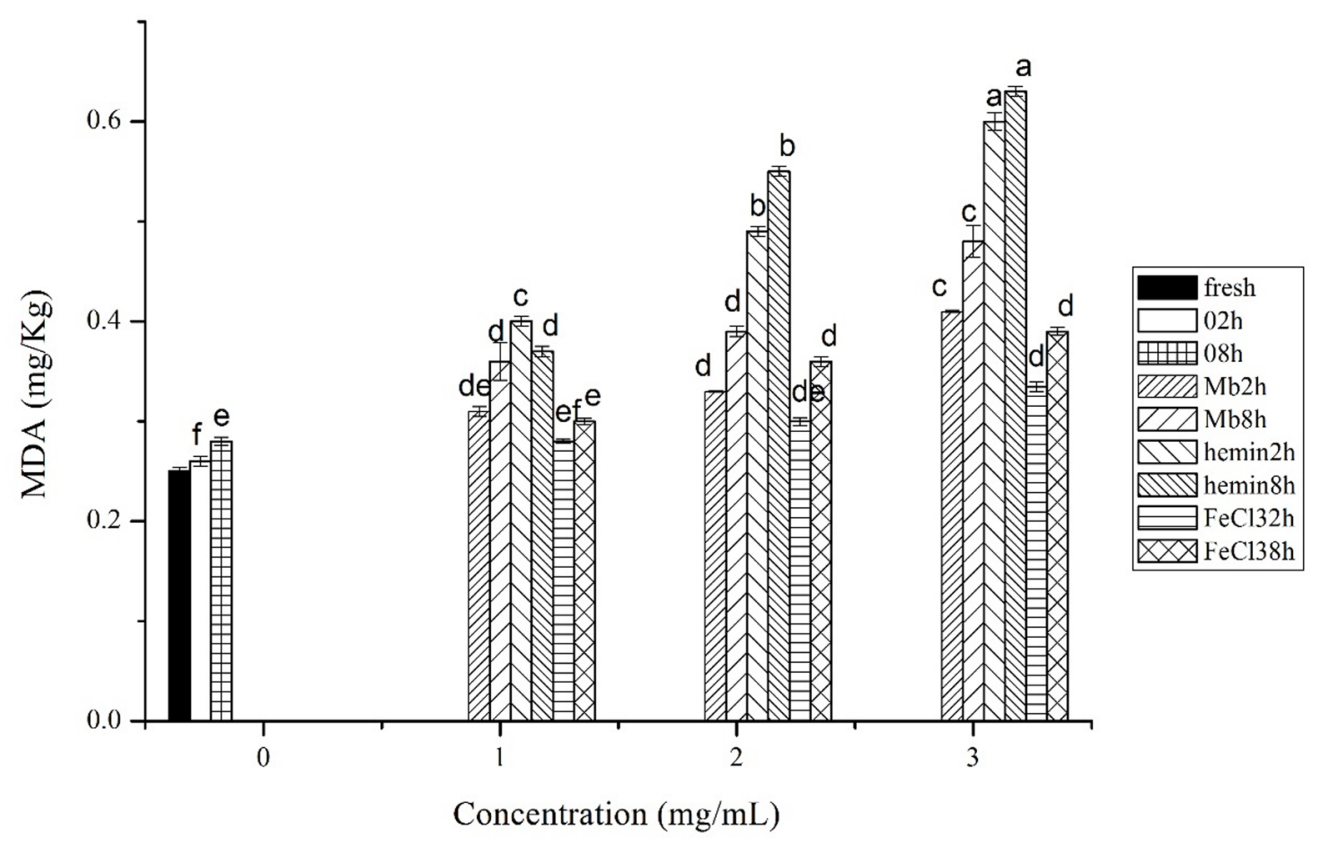

Figure 2. Malondialdehyde (MDA) formation in fresh musles and muscles incubated with phosphate buffered saline (PBS) or different concentrations of myoglobin, hemin, and $\mathrm{FeCl}_{3}$ in PBS for $2 \mathrm{~h}$ or $8 \mathrm{~h}$ of incubation time, respectively. Results are expressed as mean \pm standard error. ${ }^{\text {aff }}$ For each incubation time, values not bearing common superscripts differ significantly $(p<0.05)$. 
on the lipid concentration and the charge of the lipids [17]. In a high lipophilic environment denaturation of the protein occurs, which may result in heme release or further exposure of the heme group to the surrounding lipids [18]. As almost all lipids contain at least traces of peroxides, studies of lipid oxidation in aqueous colloidal systems suggest that the interaction between lipid hydroperoxides located at or near the droplet surface and transition metals occurs via radical chain reaction and is the most common cause of oxidative instability [19]. However, the rate of free iron induced lipid oxidation is determined by various factors such as the ratio of $\mathrm{Fe}^{3+} / \mathrm{Fe}^{2+}, \mathrm{pH}$, the presence of chelators and other inhibitors etc. [20].

\section{Impact on meat color}

Color is an important parameter that affects consumer decisions concerning the purchase of meat, $\mathrm{Mb}$ concentration and its state is accepted to be highly correlated with the color of the meat [3]. The meat in control group showed higher $\mathrm{L}^{*}$ and lower $\mathrm{a}^{*}$ values after $2 \mathrm{~h}$ and $8 \mathrm{~h}$ storage than the fresh meat (Table 1). Compared to the control, the meat by $\mathrm{Mb}$ treatment had a slightly lower $\mathrm{L}^{*}$ and higher $\mathrm{a}^{*}$ values. Hemin rendered meat a red color, with marked decrease in the lightness $\left(\mathrm{L}^{\star}\right)$ and significant increase in redness $\left(\mathrm{a}^{\star}\right)$ $(\mathrm{p}<0.05)$. However, the ferric chloride treatment led to the undesirable pale color and a reduction in redness. The resonant nature of the conjugated double bonds in the heme group is responsible for the ability of $\mathrm{Mb}$ to absorb visible light and function as a pigment [3]. The present results showed hemin could increase the redness of meat, but as chicken breast meat is considered as white meat, it might be more beneficial if it is applied to red meat. The possible explanation of the results is that association of hemin with lipid membranes may allow its penetration into the muscle cells [21], and hemin then reacted with $\mathrm{H}_{2} \mathrm{O}_{2}$ or lipid hydroperoxides to form ferryl intermediates of heme iron [22]. Furthermore, nitric oxide and carbon monoxide produced in muscle tissues could bind with hemin to form stable complexes to give bright red color [23].

\section{Impact on shear force of meat}

As shown in Figure 3, there was no significant difference in tenderness of meat at the concentration of $1 \mathrm{mg} / \mathrm{mL}$ and incubation time of $2 \mathrm{~h}$ between control and each treatment ( $p>0.05$ ). After incubated for $8 \mathrm{~h}$, treatment of muscles with $\mathrm{FeCl}_{3}$ and $\mathrm{Mb}$ resulted in the significant decrease in tenderness $(\mathrm{p}<0.05)$, while tenderness of muscles treated with 1 $\mathrm{mg} / \mathrm{mL}$ hemin had no marked change compared to that of the control ( $p>0.05$ ). The shear force of meat by $1 \mathrm{mg} / \mathrm{mL}$ hemin treatment was comparatively low, but a further increase of the hemin concentration led to a decrease in tenderness. Physicochemical changes of structural proteins by proteases or attack by ROS and lipid oxidation by-products have been identified as contributing to the variation in meat tenderness [24]. Earlier studies have proposed that oxidation of myosin by hydroxyl radical generating systems (i.e. free iron and ascorbate) results primarily in disulfide bonds, whereas heme proteins cause the formation of di-tyrosine or other non-reducible cross-links [25]. Very low levels of oxidation could result in damage in myofibrillar proteins and activate proteasome, leading to degradation of structural proteins and may have merit in improving tenderness [26]. This may explain why low concentrations of hemin improved the tenderness. The decreased tenderness at higher concentration of these components might be attributed to the formation of crosslinkages between proteins, the loss of enzyme activity, the reduction in protein solubility, and limited proteolytic activity of proteases by oxidation [24].

\section{Impact on water holding capacity of meat}

Cooking loss of meat after different treatments is shown in Figure 4. With the increase of $\mathrm{Mb}$, hemin and $\mathrm{FeCl}_{3}$ and

Table 1. Color of the meat incubated with different concentrations of myoglobin, hemin and $\mathrm{FeCl}_{3}$ respectively for different incubation time

\begin{tabular}{|c|c|c|c|c|c|c|c|}
\hline Items & & $L^{*}$ & $a^{*}$ & $\mathbf{b}^{*}$ & $L^{*}$ & $a *$ & $\mathbf{b}^{\star}$ \\
\hline 0 & & $58.96 \pm 0.39^{b}$ & $\begin{array}{l}2 \mathrm{~h} \text { of storage } \\
1.99 \pm 0.20^{\text {cd }}\end{array}$ & $2.87 \pm 0.21^{\mathrm{c}}$ & $62.82 \pm 0.75^{b c}$ & $\begin{array}{c}-8 \mathrm{~h} \text { of storage } \\
1.59 \pm 0.07^{\mathrm{d}}\end{array}$ & $2.86 \pm 0.32^{c}$ \\
\hline \multirow[t]{3}{*}{$1 \mathrm{mg} / \mathrm{mL}$} & $\mathrm{Mb}$ & $56.13 \pm 1.60^{b c}$ & $1.32 \pm 0.34^{d}$ & $6.15 \pm 0.71^{b}$ & $58.62 \pm 0.85^{c}$ & $3.77 \pm 0.33^{d}$ & $5.52 \pm 0.44^{b}$ \\
\hline & Hemin & $40.66 \pm 0.30^{d}$ & $4.07 \pm 0.60^{b}$ & $7.60 \pm 0.56^{\mathrm{ab}}$ & $39.77 \pm 0.24^{e}$ & $5.19 \pm 0.30^{\circ}$ & $5.89 \pm 0.76^{b}$ \\
\hline & $\mathrm{FeCl}_{3}$ & $62.04 \pm 0.73^{\mathrm{ab}}$ & $0.62 \pm 0.10^{e}$ & $3.16 \pm 0.46^{c}$ & $68.17 \pm 1.67^{\mathrm{ab}}$ & $0.50 \pm 0.19^{e}$ & $4.35 \pm 0.36^{b}$ \\
\hline $2 \mathrm{mg} / \mathrm{mL}$ & $\mathrm{FeCl}_{3}$ & $61.69 \pm 1.50^{a b}$ & $1.31 \pm 0.03^{d}$ & $4.31 \pm 0.34^{b c}$ & $64.37 \pm 0.94^{b}$ & $1.78 \pm 0.25^{d}$ & $4.88 \pm 0.28^{b}$ \\
\hline \multirow[t]{3}{*}{$3 \mathrm{mg} / \mathrm{mL}$} & $\mathrm{Mb}$ & $52.81 \pm 0.90^{b c}$ & $3.60 \pm 0.28^{b}$ & $9.06 \pm 0.75^{\mathrm{a}}$ & $53.67 \pm 0.66^{\mathrm{cd}}$ & $6.64 \pm 0.57^{b c}$ & $7.63 \pm 0.27^{\mathrm{ab}}$ \\
\hline & Hemin & $30.10 \pm 2.73^{\mathrm{e}}$ & $7.57 \pm 1.10^{\mathrm{a}}$ & $8.73 \pm 0.79^{\mathrm{ab}}$ & $30.54 \pm 0.31^{9}$ & $11.77 \pm 0.78^{a}$ & $2.48 \pm 0.30^{\circ}$ \\
\hline & $\mathrm{FeCl}_{3}$ & $64.68 \pm 1.08^{a}$ & $0.58 \pm 0.05^{e}$ & $5.56 \pm 0.25^{\mathrm{bc}}$ & $71.32 \pm 0.72^{a}$ & $0.97 \pm 0.28^{\mathrm{de}}$ & $7.60 \pm 0.44^{\mathrm{ab}}$ \\
\hline
\end{tabular}

Results are expressed as mean \pm standard error.

${ }^{a-g}$ Values represented with different letters in the same column are statistically different $(p<0.05)$. 


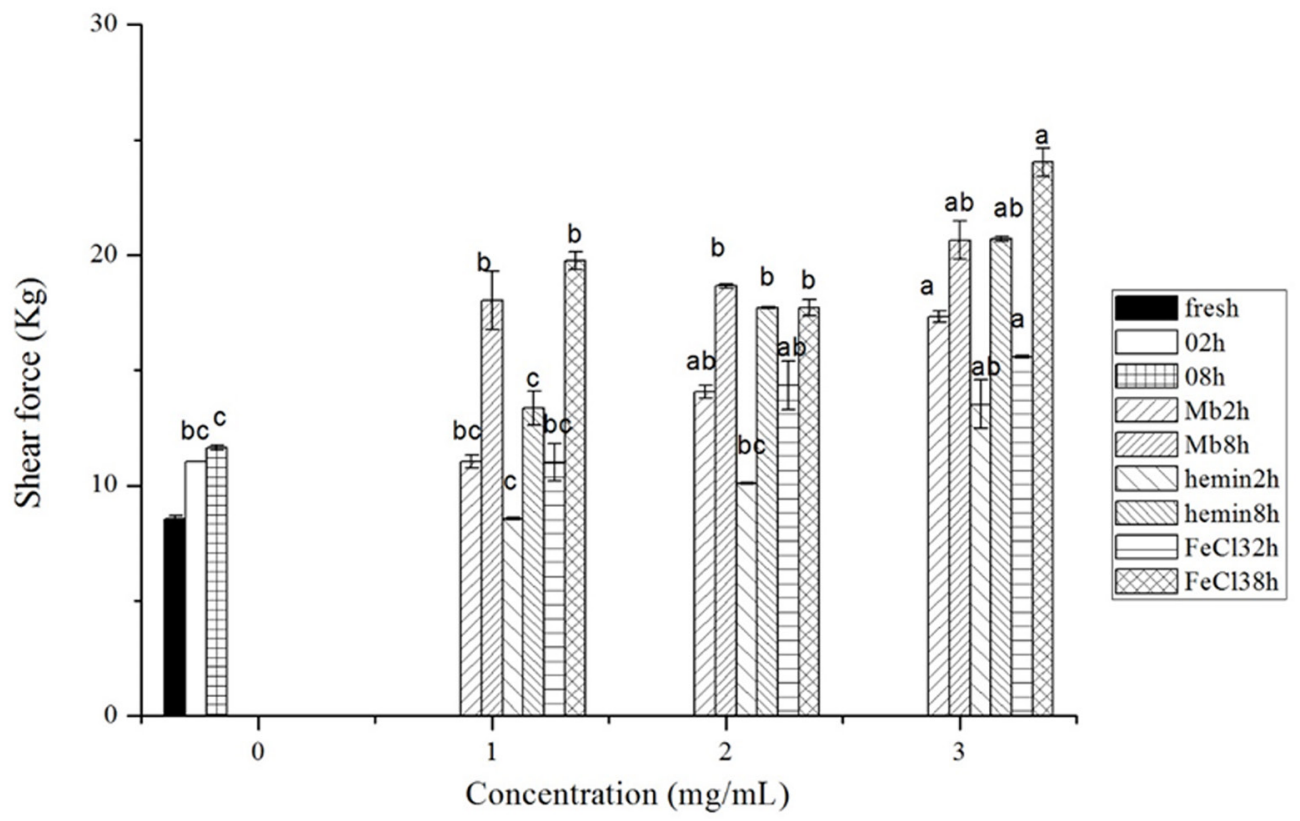

Figure 3. Shear force of fresh musles and muscles incubated with phosphate buffered saline (PBS) or different concentrations of myoglobin, hemin, and $\mathrm{FeCl}_{3}$ in PBS for $2 \mathrm{~h}$ or $8 \mathrm{~h}$ of incubation time, respectively. Results are expressed as mean \pm standard error. ${ }^{\text {acc }}$ For each incubation time, values not bearing common superscripts differ significantly $(p<0.05)$.

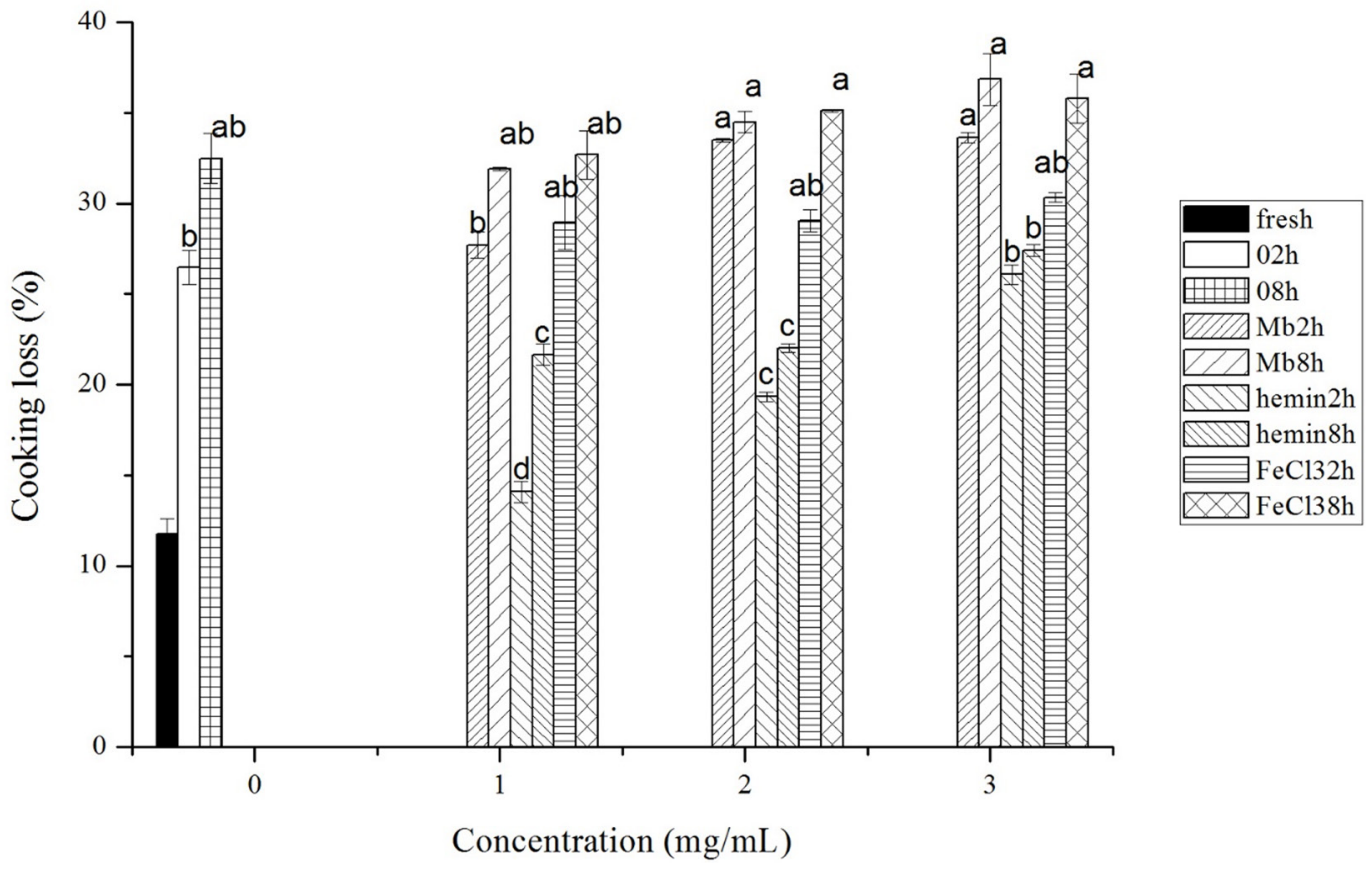

Figure 4. Cooking loss of fresh musles and muscles incubated with phosphate buffered saline (PBS) or different concentrations of myoglobin, hemin, and $\mathrm{FeCl}_{3}$ in PBS for $2 \mathrm{~h}$ or $8 \mathrm{~h}$ of incubation time, respectively. Results are expressed as mean \pm standard error. ${ }^{\mathrm{a}-\mathrm{d}}$ For each incubation time, values not bearing common superscripts differ significantly $(p<0.05)$.

treatment time, the cooking loss of meat increased. Mb treated meat had the highest cooking loss of up to $36.85 \%$ at the concentration of $3 \mathrm{mg} / \mathrm{mL}$ and incubation time of $8 \mathrm{~h}$, while hemin treated meat had the lowest cooking loss. The cooking loss in $1 \mathrm{mg} / \mathrm{mL}$ and $2 \mathrm{mg} / \mathrm{mL}$ hemin treatment group was even significantly lower than that in control groups $(\mathrm{p}<0.05)$. Low-field NMR was used to determine the water distribution, water mobility and WHC of meat. Relaxation time $\mathrm{T}_{21}, \mathrm{~T}_{22}$, and $\mathrm{T}_{23}$ at approximately 0 to $10 \mathrm{~ms}, 30$ to $100 \mathrm{~ms}$, and 200 to $300 \mathrm{~ms}$ are referred to as water that is tightly as- 
sociated with macromolecules (bound water), located in myofibrillar network (immobilized water), and located outside the myofibrillar network (free water), respectively [27]. Immobilized water and free water accounted for more than $90 \%$ of total water. It can be noted from the curves that the main component $\mathrm{T}_{22}$ was highest in fresh meat, followed by the control group, and then the meat added with hemin (Figure 5). $\mathrm{Mb}$ and $\mathrm{FeCl}_{3}$ treated groups had much lower $\mathrm{T}_{22}$ peak area but higher $\mathrm{T}_{23}$ peak area, and $\mathrm{T}_{22}$ shifted to longer relaxation time while $\mathrm{T}_{23}$ shifted to shorter time, suggesting $\mathrm{Mb}$ and $\mathrm{FeCl}_{3}$ influenced the mobility of water. Most of the water affecting WHC of meat is immobilized water that is held either by steric effects or by attraction to the bound water [28]. After heating, some immobilized water become free water, which is implicated as cooking loss [27]. For the hemin treatment, the lower cooking loss was most probably due to the strong capacity of meat to retain the immobilized water, which accounted for a large proportion of all the water.

\section{Impact on morphology of meat}

The microstructure of meat samples was observed longitudinally and transversally with hematoxylin and eosin staining and light microscopy as shown in Figure 6. The microstructure of fresh meat samples was homogeneous and compact since the muscle fibers almost entirely filled the endomysial network and muscle bundles filled the perimysial network. Hemin treated samples displayed a similar morphology with only small spaces visible from the longitudinal view. The muscle fibers in the control group were arranged less compact in comparison with the fresh and hemin group. However, the muscle in $\mathrm{Mb}$ and $\mathrm{FeCl}_{3}$ treatment groups appeared very loose and severely damaged with more and larger drip channels along the muscle fiber direction. The fluid expelled due to myofibrillar shrinkage and accumulated in the extracellular spaces might be the source of water loss [29]. And increased proteolysis or oxidation of key cytoskeletal proteins such as the intermediate filament protein desmin was associated with reduced water loss [28]. It was hypothesized that lower level of desmin degradation resulted in the shrinkage of the muscle cells that translated into spaces between muscle cells and bundles, which ultimately lead to high drip loss or purge loss during postmortem storage [30]. In muscles, lipid oxidation and protein oxidation are always coexistent [31], the generation of ROS and lipid oxidation by-products by hemin may facilitate oxidation of these proteins and reduced the formation of drip channels and extracellular space. Furthermore, changes in cellular membranes and permeability have been recognized as influencing WHC of meat, and hemin could interact with cell membranes and influence the function, phase behavior and permeability of membranes [21]. This interaction may prompt the embedding of hemin in the membrane and allowing the access of hemin into cells to react with intracellular components. Since iron deficiency is the most prevalent micronutrient deficiency worldwide, and the bioavailability of heme iron is usually more efficient than non-heme iron [32], the treatment of meat with hemin could not only improve the WHC and quality of meat, but also provide a good source of iron.

\section{CONCLUSION}

This study provides insights into the meat quality changes as influenced by myoglobin, hemin, and free iron. The results demonstrated that even though the addition hemin could result in higher levels of ROS production and lipid oxidation, it significantly improved the water holding capacity of

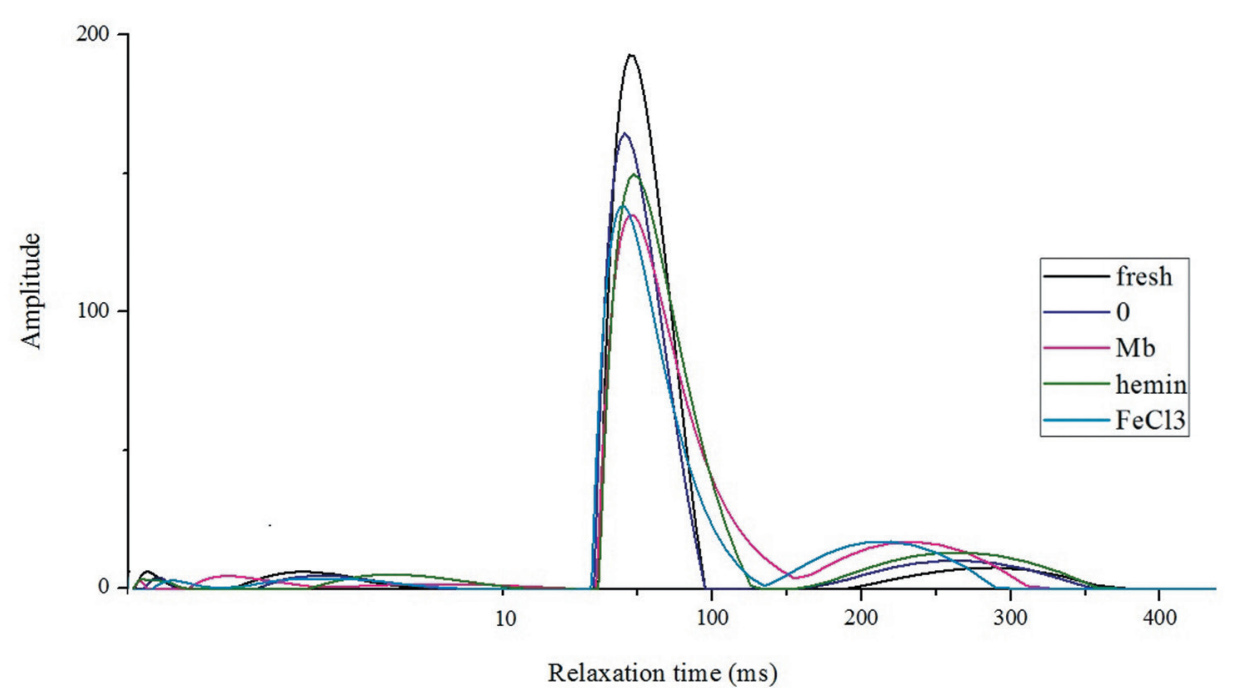

Figure 5. Representative distribution of $\mathrm{T}_{2}$ relaxation times for fresh muscles and muscles incubated with phosphate buffered saline (PBS) or 3 $\mathrm{mg} / \mathrm{mL}$ myoglobin, hemin and $\mathrm{FeCl}_{3}$ respectively for $8 \mathrm{~h}$. 

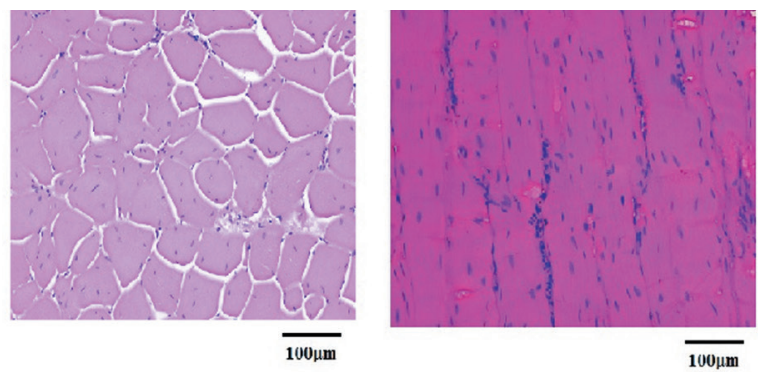

fresh
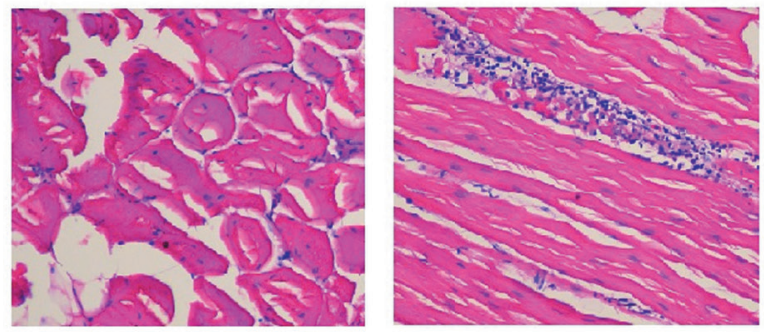

\section{(1)

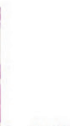

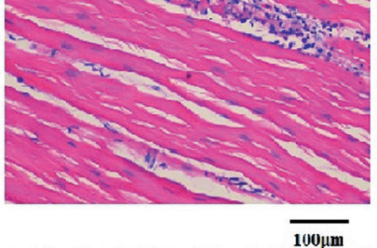

$\overline{100 \mu \mathrm{m}}$
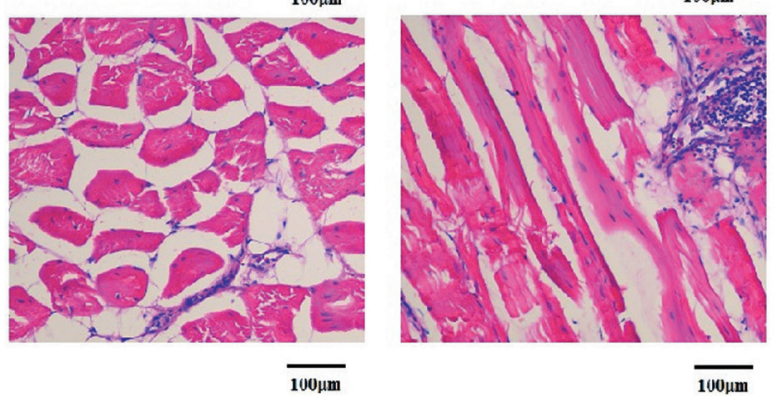
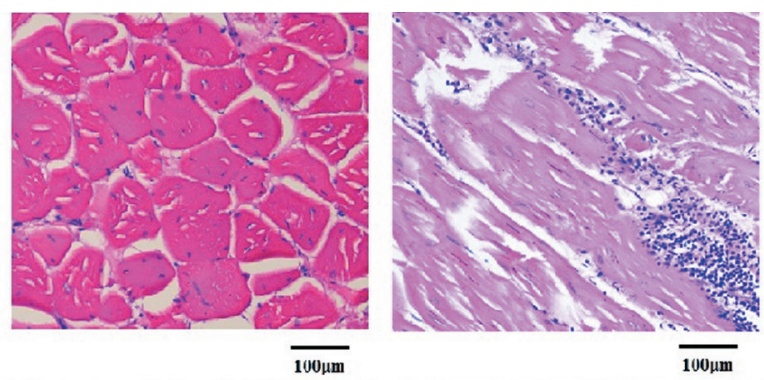

0
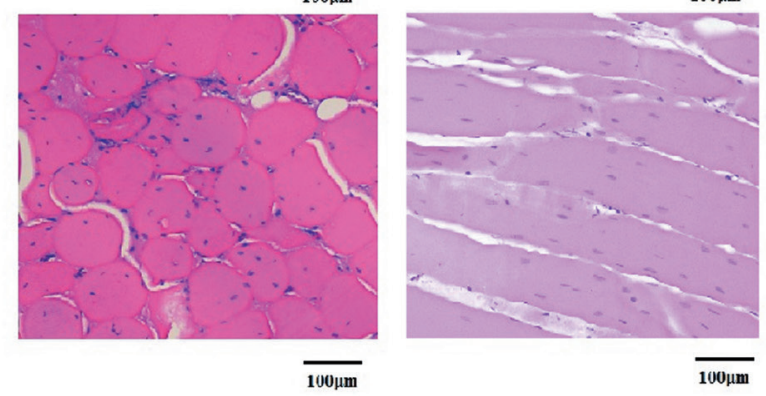

hemin

\section{$\mathrm{FeCl3}$}

Figure 6. Representative images of hematoxylin and eosin staining of fresh muscles and muscles incubated with phosphate buffered saline or 3 $\mathrm{mg} / \mathrm{mL}$ myoglobin, hemin and $\mathrm{FeCl}_{3}$ respectively for $8 \mathrm{~h}(\times 200)$.

meat and preserved the integrity of muscle. The results indicate that hemin may be an innovative substance to improve the quality of meat, and further studies will be needed to clarify how hemin participate in the structure changes and WHC of meat, as well as the transformation of different forms of iron in meat. Hemin, a natural component in meat, may have the potential to be used in the industry to minimize the water loss and improve meat quality.

\section{CONFLICT OF INTEREST}

We certify that there is no conflict of interest with any financial organization regarding the material discussed in the manuscript.

\section{ACKNOWLEDGMENTS}

This study was supported by National Natural Science Foundation of China (31972137), China Agriculture Research System (CARS-41), Primary Research \& Development Plan of Jiangsu Province (BE2017392), the Priority Academic Program Development of Jiangsu Higher Education Institutions, Overseas Expertise Introduction Center for Discipline
Innovation (111 Center) On Quality \& Safety Control and Nutrition of Muscle Food (B14023).

\section{REFERENCES}

1. Ordway GA, Garry DJ. Myoglobin: an essential hemoprotein in striated muscle. J Exp Biol 2004;207:3441-6. https://doi. org/ 10.1242/jeb.01172

2. Giaretta N, Giuseppe AMAD, Lippert M, Parente A, Maro AD. Myoglobin as marker in meat adulteration: a UPLC method for determining the presence of pork meat in raw beef burger. Food Chem 2013;141:1814-20. https://doi.org/ 10.1016/j.foodchem.2013.04.124

3. Suman SP, Joseph P. Myoglobin chemistry and meat color. Annu Rev Food Sci Technol 2013;4:79-99. https://doi.org/ 10.1146/annurev-food-030212-182623

4. Carlsen CU, Moller JKS, Skibsted LH. Heme-iron in lipid oxidation. Coord Chem Rev 2005;249:485-98. https://doi. org/10.1016/j.ccr.2004.08.028

5. Maitra D, Byun J, Andreana PR, et al. Reaction of hemoglobin with HOCl: mechanism of heme destruction and free iron release. Free Radic Biol Med 2011;51:374-86. https://doi.org/ 10.1016/j.freeradbiomed.2011.04.011 
6. Min B, Cordray JC, Ahn DU. Effect of $\mathrm{NaCl}$, myoglobin, Fe (II), and Fe (III) on lipid oxidation of raw and cooked chicken breast and beef loin. J Agric Food Chem 2010;58:600-5. https:// doi.org/10.1021/jf9029404

7. Grunwald EW, Richards MP. Studies with myoglobin variants indicate that released hemin is the primary promoter of lipid oxidation in washed fish muscle. J Agric Food Chem 2006; 54:4452-60. https://doi.org/10.1021/jf0603228

8. Mokrani A, Krisa S, Cluzet S, et al. Phenolic contents and bioactive potential of peach fruit extracts. Food Chem 2016; 202:212-20. https://doi.org/10.1016/j.foodchem.2015.12. 026

9. Sorensen G, Jorgensen SS. A critical examination of some experimental variables in the 2-thiobarbituric acid (TBA) test for lipid oxidation in meat products. Z Lebensm Unters Forsch 1996;202:205-10. https://doi.org/10.1007/BF01263541

10. Meullenet JF, Jonville E, Grezes D, Owens CM. Prediction of the texture of cooked poultry pectoralis major muscles by near-infrared reflectance analysis of raw meat. J Texture Stud 2004;35:573-85. https://doi.org/10.1111/j.1538-7836. 2004.01165.x-i1

11. Bertram HC, Oksbjerg N, Young JF. NMR-based metabonomics reveals relationship between pre-slaughter exercise stress, the plasma metabolite profile at time of slaughter, and waterholding capacity in pigs. Meat Sci 2010;84:108-13. https:// doi.org/10.1016/j.meatsci.2009.08.031

12. Lan X, Zhang X, Zhou G, Wu C, Li C, Xu X. Electroacupuncture reduces apoptotic index and inhibits p38 mitogen-activated protein kinase signaling pathway in the hippocampus of rats with cerebral ischemia/reperfusion injury. Neural Regen Res 2017;12:409-16. https://doi.org/ 10.4103/1673-5374.202944

13. Gueraud F, Atalay M, Bresgen N, et al. Chemistry and biochemistry of lipid peroxidation products. Free Radic Res 2010; 44:1098-124. https://doi.org/10.3109/10715762.2010.498477

14. Yu Y, Mukherjee A, Nilges MJ, Hosseinzadeh P, Miner KD, $\mathrm{Lu}$ Y. Direct EPR observation of a tyrosyl radical in a functional oxidase model in myoglobin during both $\mathrm{H}_{2} \mathrm{O}_{2}$ and $\mathrm{O}_{2}$ reactions. J Am Chem Soc 2014;136:1174-7. https://doi.org/10. 1021/ja4091885

15. Rhee KS, Ziprin YA. Lipid oxidation in retail beef, pork and chicken muscles as affected by concentrations of heme pigments and nonheme iron and microsomal enzymic lipid peroxidation activity. J Food Biochem 1987;11:1-15. https:// doi.org/10.1111/j.1745-4514.1987.tb00109.x

16. Roginsky V, Zheltukhina GA, Nebolsin VE. Efficacy of metmyoglobin and hemin as a catalyst of lipid peroxidation determined by using a new testing system. J Agric Food Chem 2007;55:6798-806. https://doi.org/10.1021/jf0714362

17. Vernier G, Chenal A, Vitrac H, Barumandzadhe R, Montagner C, Forge V. Interactions of apomyoglobin with membranes: mechanisms and effects on heme uptake. Protein Sci 2007;16:
391-400. https://doi.org/10.1110/ps.062531207

18. Baron CP, Andersen HJ. Myoglobin-induced lipid oxidation. A review. J Agric Food Chem 2002;50:3887-97. https://doi. org/10.1021/jf011394w

19. Mozuraityte R, Rustad T, Storro I. The role of iron in peroxidation of polyunsaturated fatty acids in liposomes. J Agric Food Chem 2008;56:537-43. https://doi.org/10.1021/jf071 6073

20. Cheng Z, Li Y. What is responsible for the initiating chemistry of iron-mediated lipid peroxidation: an update. Chem Rev 2007;107:748-66. https://doi.org/10.1021/cr040077w

21. Giri RP, Mukhopadhyay MK, Basak UK, et al. Continuous uptake or saturation- investigation of concentration and surface-packing-specific hemin interaction with lipid membranes. J Phys Chem B 2018;122:7547-54. https://doi.org/ 10.1021/acs.jpcb.8b03327

22. Faustman C, Sun Q, Mancini R, Suman SP. Myoglobin and lipid oxidation interactions: mechanistic bases and control. Meat Sci 2010;86:86-94. https://doi.org/10.1016/j.meatsci. 2010.04.025

23. Zhou C, Tan S, Li J, Chu X, Cai K. A novel method to stabilize meat colour: ligand coordinating with hemin. J Food Sci Technol 2014;51:1213-7. https://doi.org/10.1007/s13197012-0625-Z

24. Zhang W, Xiao S, Ahn DU. Protein oxidation: basic principles and implications for meat quality. Crit Rev Food Sci Nutr 2013;53:1191-201. https://doi.org/10.1080/10408398.2011. 577540

25. Lund MN, Luxford C, Skibsted LH, Davies MJ. Oxidation of myosin by haem proteins generates myosin radicals and protein cross-links. Biochem J 2008;410:565-74. https://doi. org/10.1042/BJ20071107

26. Malheiros JM, Braga CP, Grove RA, et al. Influence of oxidative damage to proteins on meat tenderness using a proteomics approach. Meat Sci 2019;148:64-71. https://doi. org/10.1016/j.meatsci.2018.08.016

27. Shao JH, Deng YM, Jia N, et al. Low-field NMR determination of water distribution in meat batters with $\mathrm{NaCl}$ and polyphosphate addition. Food Chem 2016;200:308-14. https:// doi.org/10.1016/j.foodchem.2016.01.013

28. Huff-Lonergan E, Lonergan SM. Mechanisms of waterholding capacity of meat: the role of postmortem biochemical and structural changes. Meat Sci 2005;71:194-204. https:// doi.org/10.1016/j.meatsci.2005.04.022

29. Barbut S, Zhang L, Marcone M. Effects of pale, normal, and dark chicken breast meat on microstructure, extractable proteins, and cooking of marinated fillets. Poult Sci 2005; 84:797-802. https://doi.org/10.1093/ps/84.5.797

30. Zhang WG, Lonergan SM, Gardner MA, Huff-Lonergan E. Contribution of postmortem changes of integrin, desmin and $\mu$-calpain to variation in water holding capacity of pork. Meat Sci 2006;74:578-85. https://doi.org/10.1016/j.meatsci. 


\subsubsection{8}

31. Wang Z, He Z, Emara AM, Gan X, Li H. Effects of malondialdehyde as a byproduct of lipid oxidation on protein oxidation in rabbit meat. Food Chem 2019;288:405-12. https://doi.org/ 10.1016/j.foodchem.2019.02.126
32. Lai JF, Dobbs J, Dunn MA. Evaluation of clams as a food source of iron: total iron, heme iron, aluminum, and in vitro iron bioavailability in live and processed clams. J Food Compost Anal 2012;25:47-55. https://doi.org/10.1016/j.jfca.2011.07. 004 